\title{
Loss of Only Child Family in China: Psychological Effect
}

\section{Yu Yu and Shui-Yuan Xiao*}

Department of Social Medicine and Health Management, School of Public Health, Central South University, China

*Corresponding author: Shui-Yuan Xiao MD, Department of Social Medicine and Health Management, School of Public Health, Central South University, Upper Mayuanlin Road 238, Changsha, Hunan 410008, China, Tel: +86-84505459; Fax: 84805459; E-mail: xiaosy@csu.edu.cn

Receiving date: August 6, 2015; Accepted date: August 18, 2015; Published date: August 21, 2015

Copyright: ( $2015 \mathrm{Yu} \mathrm{Y,} \mathrm{et} \mathrm{al.} \mathrm{This} \mathrm{is} \mathrm{an} \mathrm{open-access} \mathrm{article} \mathrm{distributed} \mathrm{under} \mathrm{the} \mathrm{terms} \mathrm{of} \mathrm{the} \mathrm{Creative} \mathrm{Commons} \mathrm{Attribution} \mathrm{License,} \mathrm{which} \mathrm{permits} \mathrm{unrestricted} \mathrm{use,}$ distribution, and reproduction in any medium, provided the original author and source are credited.

\section{Introduction}

Thirty years after its implementation as a national policy, the "one child per family" policy has reduced about 400 million births in China. Despite its effectiveness in controlling population growth, the "one child per family" policy has also engendered a newly vulnerable group----"loss of only-child family" (LOCF) due to the increased risk of losing their only-child from accidents or diseases in modern society.

LOCF refers to the family that lost their only child yet cannot or don't want to give birth to or adopt another child. It is one of the side effects of the "one child per family" policy that is unique to China and has long been neglected. It is only recently that LOCFs has begun to raise public concern with its increasing number. In 2011, the number of LOCFs in China exceeded 1 million [1] and is estimated to reach10 million by 2035 [2]. Behind these huge numbers are great economic burden and psychosocial pressure extoled on both the family and the society, of which psychological trauma has been the core issue confronting LOCFs.

Loneliness is the most common psychological problem facing LOCFs. Unlike the western culture that values individualism and independence, Chinese culture emphasizes collectivism and familism. The Chinese society is based on close-knit family relationship, where children are seen as the only continuation of family bloodline and are expected to support their old parents when they grow up. Losing the only child often means a break of the family line and a lonely old age with no one to rely on in a seriously flawed Chinese health system [3]. Besides, many of the LOCFs cut off every connection with others and isolate themselves from society just because they don't want to be reminded of sad memories in public [4], which, in turn, further aggravates their loneliness. What's worse, some females are abandoned by their husbands after losing their only child because their husbands want to have babies with other young fertile women [4], which usually put those females into an extremely isolated situation.

Other psychological traumas facing LOCFs include long-term grief, anxiety, nervousness and depression [4], which is often accompanied with somatic symptoms ranging from headache and insomnia to serious life-threatening diseases such as cancer. Some even try to commit suicide under the double blow of both psychological and physical sufferings.

The psychological traumas of LOCFs are well recognized, yet few interventions have been implemented to reduce their psychological problems. The only approach for them to seek emotional support is to establish on-line peer support groups such as QQ group (a chatting service similar to Facebook) where LOCFs can share their experiences and feelings with each other, yet this is only available to a few LOCFs familiar with internet. More research to explore effective interventions to improve the mental health of LOCFs are in urgent need.

\section{Funding}

The study was supported by Hunan Provincial Innovation Foundation for Postgraduate, No. CX2015B058.

\section{References}

1. Ministry of Health (2010) yearbook of health statistics in China.

2. Huang J (2012) Losing their only child. Global Times Online.

3. Li Y, Wu S (2013) Health care for the elderly who lose their only child in china. Lancet 381:536.

4. Li Y (2013) A perspective on health care for the elderly who lose their only child in China. Scand J Public Health 41: 550-552. 